\title{
Cerebral vasospasm in shunt infection
}

\author{
Martin H. Deininger · Ansgar Berlis • \\ Juergen Buttler
}

\begin{abstract}
Objective In bacterial shunt infection, CNS inflammation is a frequently observed complication that may cause vascular complications including vasospasms. Here, we describe the first patient with shunt infection-induced cerebral vasospasms.

Methods A 35 year old woman with a ventriculoperitoneal shunt that was implanted years before developed facial nerve palsy and somnolence one week before admission to the hospital.

Results After admission, the shunt was removed, and an external ventricular drainage was inserted. Microbiological analyses revealed coagulase-negative Staphylococcus on abdominal and cranial catheters. Follow-up NMR showed infarctions. Transcranial doppler sonography and cerebral arteriography revealed severe generalized cerebral vasospasms. Inspite of triple- $\mathrm{H}$ therapy and intraarterial spasmolysis, bilateral anterior and media artery infarction evolved. The patient was dismissed in a vegetative state.

Conclusions This case shows that severe cerebral vasospasms are a serious complication in patients with bacterial shunt infection that should be considered in patients, that don't improve following adequate antibiotic treatment.
\end{abstract}

M. H. Deininger $(\varangle) \cdot$ J. Buttler

Department of General Neurosurgery, University of Freiburg Medical School, Breisacher Str. 64, Freiburg 79106, Germany e-mail: martin.deininger@uni-tuebingen.de

A. Berlis

Department of Neuroradiology, University of Freiburg Medical School, Freiburg, Germany
Keywords Infarction - Meningitis - Shunt - Vasospasm

\section{Introduction}

Infection remains a serious complication in shunt patients. Mortality rates have remained unaltered despite the development of powerful antibiotic treatment strategies.

Two different types of infection can be differentiated: early and delayed. Early shunt infection rates range from $0.3-15 \%[1,2]$, with a mortality rate ranging from $1.5-22 \%[3,4]$. Many factors are associated with shunt infection, including the age of the patient, the etiology of hydrocephalus, and the type of shunt implanted [1-5]. Delayed shunt infections are thought to be independent of the initial shunt surgery. About $12 \%$ of all shunt infections are delayed, following other inflammatory conditions like appendicitis, or iatrogenic perforation [6].

In shunt infection, bacterial CNS infection is a common complication. The reasons for the occasional grim outcome of bacterial CNS infection are unknown, however, cerebral vasospasms are a documented, but rarely observed phenomenon [7-10]. In a prospective study of adults with bacterial meningitis, alterations of the cerebral vessel systems were observed in 13 of 27 patients with focal deficits and no improvement after three days of antibiotic therapy [11]. Those who survive risk intellectual, cognitive, and neurological deficits [12].

We now demonstrate the case of a patient with coagulase-negative Staphylococcus delayed ventriculoperitoneal shunt infection-associated bacterial CNS infection with severe vasospasms, a complication that needs to be taken into account in patients that don't improve after adequate antibiotic treatment. 


\section{Case report}

A 35 year old woman who had received a ventriculoperitoneal shunt (VPS) because of a Dandy-Walker cyst years ago and seronegative spondylarthropathy treated with corticosteroids fainted on a hot day while working in the fields. The following days, she was described to have become progressively apathetic, and finally was brought to a local hospital. Here, clinical signs of bacterial CNS infection: neck rigidity, somnolence and in addition facial nerve palsy and divergent bulbi were described. She was transferred to our department with the diagnosis of VP shunt malfunction.

After admission to our department, approximately seven days after the onset of the symptoms, the ventriculoperitoneal shunt (VPS) was punctuated, with a $5 \mathrm{~cm} \mathrm{H}_{2} \mathrm{O}$ opening pressure. The aspired cerebrospinal fluid (CSF) was yellow, so the VPS was removed, an external ventricular drainage (EVD) was inserted, and vancomycin and ceftriaxone was given. Microbiological analyses revealed coagulase-negative Staphylococcus on the shunt system.

At the second day, the patient became comatose, endotracheal intubation was necessary. An EEG revealed general alteration, no epilepsy-specific potentials were observed. A cranial MRI scan with MR-angiography showed infarcts in bilateral arteria and middle cerebral artery territories (Fig. 1A-D). In a transcranial doppler sonography, cerebral vasospasms were detected. Cerebral angiography revealed generalized vasospasms (Fig. 2A-D), that were treated with intraarterial nimodipine and papaverine on two consecutive days with postinterventional improvement. The TCD as well as the angiogram of the basilar artery showed marked improvement after the first intraarterial spasmolysis. The second intraarterial spasmolysis was performed only in the anterior circulation, and only slight improvement was observed. After the procedures, intravenous nimodipine was continuously administered and triple-H therapy was initiated (hyperdynamic hypertensive hypervolemia). With this regimen, transcranial doppler signals continuously improved, but remained elevated until day eight after admission.

On the 8th day after admission, when the laboratory symptoms of bacterial CNS infection had ceased and clinical improvement was observed, artificial coma was terminated. The patient, however, remained comatose, was tracheotomized and finally transferred to a rehabilitation unit.

\section{Discussion}

This is the first description of a patient with delayed ventriculoperitoneal shunt infection-associated severe vasospasms.
Fig. 1 MRI scans show infarcts at the basal ganglia and the genu of corpus callosum as a result from cerebral vasospasm. T1-weighted image (A), T2-weighted image (B), T1-weighted image with intravenous gadolinium application (C), diffusionweighted image (D)
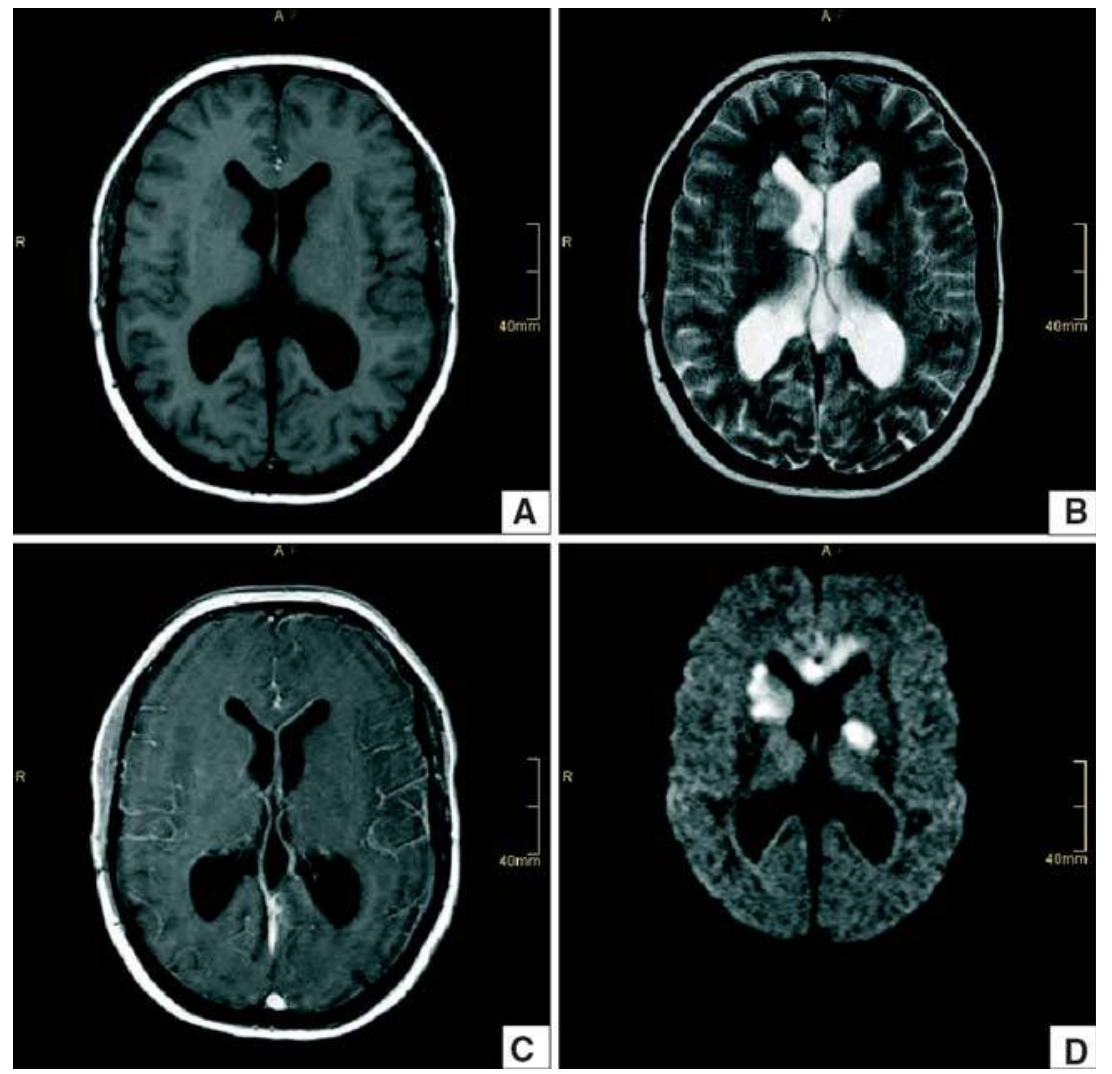
Fig. 2 Cerebral angiogram revealing generalized cerebral vasospasm especially with high-grade vessel narrowing at both distal ICAs and basilar trunk as well with lower grade vessel narrowing of the other cerebral arteries. Right internal cerebral artery (A), left internal cerebral artery $(\mathbf{B})$, right vertebral artery $(\mathbf{C})$, left vertebral artery one day after spasmolysis (D)
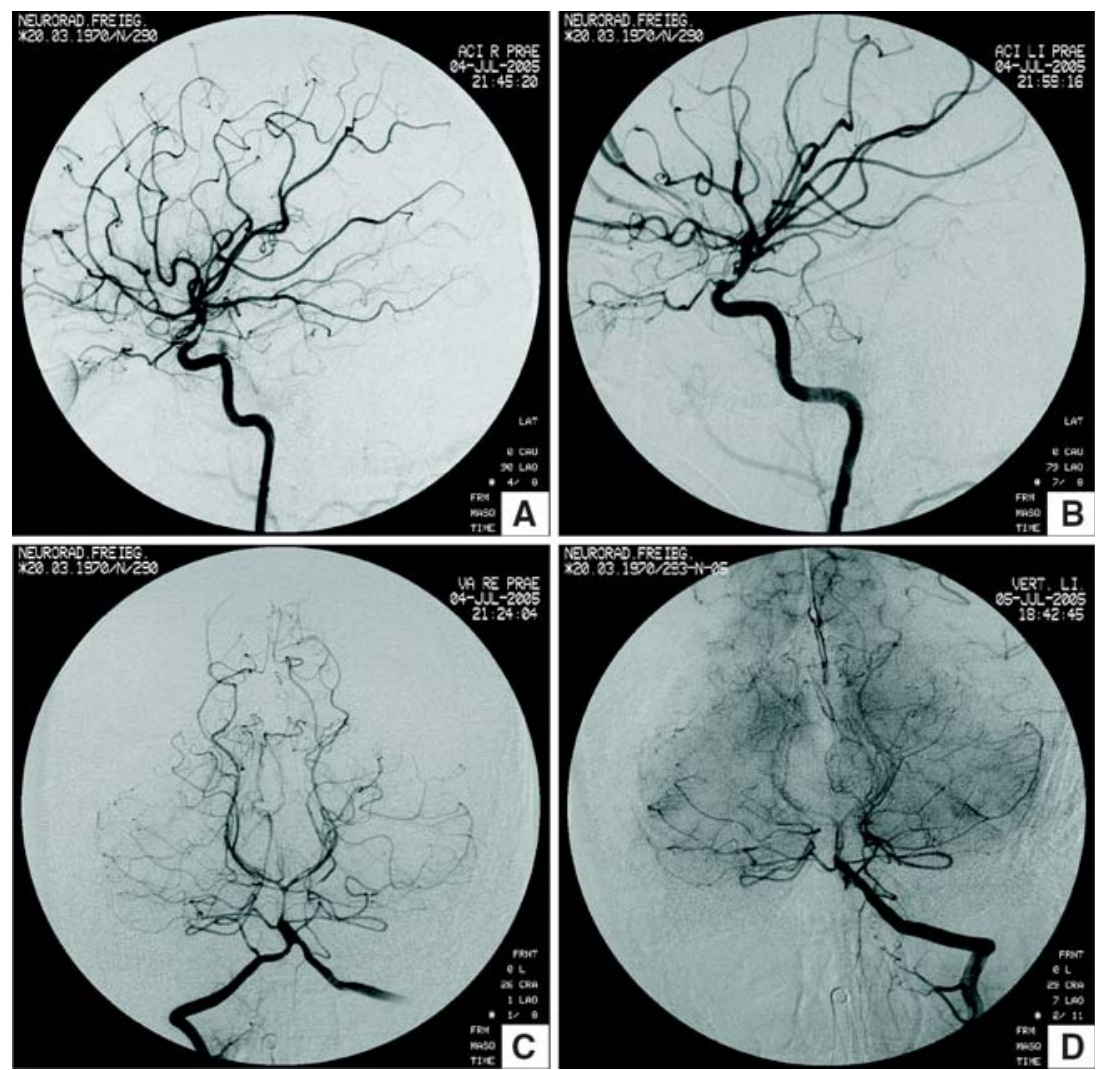

Vasospasms in patients with bacterial CNS infection, are a rarely observed but known phenomenon that may attribute to the occasionally grim progression of the disease, and should be taken into account when treating these patients.

While distinct pathophysiological phenomena during bacterial CNS infection have been described, the exact mechanism or moreover therapies to ameliorate the disease are lacking [13-15]. Previous studies demonstrated a high incidence of vascular involvement as a complication of bacterial CNS infection [16, 17]. Elevated cerebral blood flow velocities in the middle cerebral artery were observed in $18 / 22$ patients, markedly increased systolic peak velocities (CBFV of $>210 \mathrm{~cm} / \mathrm{s})$ in 7 patients [10]. In 27 selected patients with complicated bacterial meningitis, vascular involvement was observed in 9/27 patients [11] and focal hypoperfusion was observed in 13/14 consecutive patients with bacterial meningitis [18].

While the exact mechanisms of elevated cerebral blood flow during bacterial CNS infection remain obscure, it was suggested that inflammatory cytokines are the predominant mechanism of flow elevations [19].

Ischaemic lesions and seizures, thought to be predictors of a negative outcome, are associated with severe cerebral vasospasm and are clinically characterized by reduction of consciousness and high cerebral blood flow velocities
$[20,10]$. Vascular changes during the time course of bacterial CNS infection reach their maximum 3-7 days after the first onset of symptoms [21, 10].

We conclude from these data that the high incidence of vascular involvement as a complication of bacterial CNS inflammation justifies the routine examination by transcranial doppler sonography in patients with shunt infection.

\section{References}

1. Schoenbaum SC, Gardner P, Shillito J. Infections of cerebrospinal fluid shunts: epidemiology, clinical manifestations, and therapy. J Infect Dis 1975;131:543-52.

2. Shurtleff DB, Stuntz JT, Hayden PW. Experience with 1201 cerebrospinal fluid shunt procedures. Pediatr Neurosci 1985/86; 12:49-57.

3. George R, Leibrock L, Ebstein M. Long term analysis of cerebrospinal fluid shunt infections. A 25 years experience. J Neurosurg 1997;51:804-11.

4. Younger JJ, Simmons JC, Barnett FF. Failure of single dose intraventricular vancomycin for cerebrospinal fluid shunt surgery prophylaxis. Pediatr Infect Dis J 1987;6:212-3.

5. Gardner P, Leipzig T, Phillips P. Infections of central nervous system shunts. Med Clin North Am 1985;69:297-314.

6. Vinchon M, Lemaitre MP, Vallee L, Dhellemmes P. Late shunt infection: incidence, pathogenesis, and therapeutic implications. Neuropediatrics 2002;33:169-73.

7. Ferris EJ, Rudikoff JC, Shapiro JH. Cerebral angiography of bacterial infection. Radiology 1968;90:727-34. 
8. Leeds NE, Goldberg HI. Angiographic manifestations in cerebral inflammatory disease. Radiology 1971;98:595-604.

9. Swartz MN. Bacterial meningitis: more involved than just the meninges. N Engl J Med 1984;311:912-4.

10. Ries S, Schminke U, Fassbender K, Daffertshofer M, Steinke W, Hennerici M. Cerebrovascular involvement in the acute phase of bacterial meningitis. J Neurol 1997;244:51-5.

11. Pfister HW, Borasio GD, Dinagl U, Bauer M, Einhäupl KM. Cerebrovascular complications of bacterial meningitis in adults. Neurology 1992;42:1497-504.

12. Shurtleft DB, Foltz EL, Loeser JD. Hydrocephalus: a definition of its progression and relationship to intellectual function, diagnosis, and complications. Am J Dis Child 1973;125:688-93.

13. Igarashi M, Gimartin RC, Gerald B, Wilburn F, Jabbour JT. Cerebral arteritis and bacterial meningitis. Arch Neurol 1984;41:531-35.

14. Pfister HW. Die komplizierte eitrige Meningitis des Erwachsenen: weiterhin hohe Letalität durch Vaskulitis und Hirndruck. Nervenarzt 1989;60:249-54.

15. Pfister HW, Feiden W, Einhäupl KM. Spectrum of complications during bacterial meningitis in adults. Arch Neurol 1993;50:575-81.
16. Goldman HB. Is heparin really indicated in bacterial meningitis? Arch Neurol 1994;54:13.

17. Lebel MH, Freij BJ, Syrogiannopoulos GA, et al. Dexamethasone therapy for bacterial meningitis. N Engl J Med 1988;319:964-71.

18. Förderreuther S, Tatsch K, Einhäupl KM, Pfister HW. Abnormalities of cerebral blood flow in the acute phase of bacterial meningitis in adults. J Neurol 1992;239:431-36.

19. Fassbender K, Ries S, Schminke U, Schneider S, Hennerici M. Inflammatory cytokines in CSG in bacterial meningitis: association with altered blood flow velocities in basal cerebral arteries. J Neurol Neurosurg Psychiatry 1996;61:57-61.

20. Müller M, Merkelbach S, Huss GP, Schmirgk K. Clinical relevance and frequency of transient stenoses of the middle and anterior cerebral arteries in bacterial meningitis. Stroke 1995;26:1399-403.

21. Haring HP, Rötzer HK, Reindl H, et al. Time course of cerebral blood flow velocity in central nervous system infections. Arch Neurol 1993;50:98-101. 